\title{
Free open access medical education for point of care ultrasound: content discovery and resource evaluation
}

\author{
Simone Rudnin, Josh Greenstein, Abbas Husain \\ Department of Emergency Medicine, Northwell Health Staten Island University Hospital, Staten Island, NY, USA
}

\section{INTRODUCTION}

Free open access medical education (FOAM) harnesses the power of various digital communication platforms such as websites, blogs, tweets, podcasts, videos, and social media applications. This online community contributes to sharing ideas and "accelerates the translation of research into clinical practice."1 In this paper, we will explore the use of FOAM to learn and teach pointof-care ultrasound (POCUS) as images and videos of ultrasonography are easily posted and shared online with clinical vignettes and procedure descriptions.

\section{CONTENT DISCOVERY}

POCUS FOAM content has grown exponentially, providing clinicians an opportunity to expand their knowledge and expertise. Many FOAM websites highlight content within emergency medicine (EM) and its various subspecialties. Recently, articles have been published on the critical appraisal of FOAM ${ }^{2}$ and FOAM mobile apps. ${ }^{3}$ However, there is no literature evaluating POCUS FOAM resources, which prompted us to create this review.

Searching for content specific FOAM education may be difficult given the extensive content available. Websites specific for searching FOAM content, such as 'FOAM Search' (https://www. googlefoam.com) help with finding focused FOAM (F_FOAM). ${ }^{4}$ FOAM Search allows you to either broadly search for FOAM material or to choose from their subcategories of F_FOAM. Many popular FOAM websites have subcategories that provide archives to ultrasound videos such as 'Life in The Fast Lane' while others provide solely F_FOAM video and image archives such as 'The Pocus Atlas.4 A report of our search results is presented in Table 1.

Some F_FOAM websites such as '5 Minute Sono' provide podcasts in addition to their archivebased websites. Podcasts are popular in the FOAM world since they provide a simplified process of downloading and listening to lectures. ${ }^{5}$ As such, learners can access the podcast content anytime and anywhere.

Mobile apps are easily accessible and have become quite appealing to clinicians. Apps like 'Pocket Emergency Ultrasound' provide sample images of each type of POCUS exam with reference ranges for each category to quickly remind the user of normal/abnormal values. 'SonoSupport' is another great app for ultrasound guided procedures. The SonoSupport app provides you the pertinent information to perform a variety of POCUS applications with background information and tutorials on best practices in POCUS such as probe selection, obtaining views, images of
eISSN: 2383-4625

Received: 26 July 2020

Revised: 3 December 2020

Accepted: 8 December 2020

Correspondence to: Simone Rudnin Department of Emergency Medicine, Northwell Health Staten Island University Hospital, 475 Seaview Ave, Staten Island, NY 10305, USA

E-mail: srudnin@northwell.edu ORCID

https://orcid.org/0000-0001-6825-6625

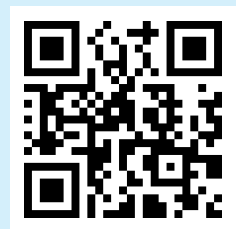

How to cite this article:

Rudnin S, Greenstein J, Husain A. Free open access medical education for point of care ultrasound: content discovery and resource evaluation. Clin Exp Emerg Med 2021;8(1):71-73. https://doi.org/10.15441/ ceem. 20.093

This is an Open Access article distributed under the terms of the Creative Commons Attribution Non-Commercial License (https:// creativecommons.org/licenses/by-nc/4.0/). 
Table 1. Select free open access medical education websites, podcasts, and mobile apps that are dedicated to EM POCUS

\begin{tabular}{|c|c|c|c|}
\hline Name & $\begin{array}{l}\text { Website, } \\
\text { podcast or app }\end{array}$ & Description & URL \\
\hline 5 Minute Sono & Website & Five-minute basic how-to-do specific US exams & https://www.coreultrasound.com/5ms \\
\hline The Pocus Atlas & Website & Image based database of POCUS findings & http://www.thepocusatlas.com \\
\hline SonoWorld & Website & Case based ultrasound findings and links POCUS news and lectures. & https://sonoworld.com/ \\
\hline Ultrasound of The Week & Website & Case based ultrasounds with information about the pathology & $\begin{array}{l}\text { https://www.coreultrasound.com/category/ultra- } \\
\text { sound-of-the-week/ }\end{array}$ \\
\hline 5 Minute Sono & Podcast & $\begin{array}{l}\text { Five minutes or less of POCUS especially for critically ill patients that is } \\
\text { concise and brief allowing users to review techniques even if "on shift' }\end{array}$ & $\begin{array}{l}\text { https://podcasts.apple.com/us/podcast/5-minute-so- } \\
\text { no/id1063071579 }\end{array}$ \\
\hline Ultrasound G.E.L. Podcast & Podcast & $\begin{array}{l}\text { GEL which stands for gathering evidence from literature, reviews and } \\
\text { discusses recent POCUS literature }\end{array}$ & http://www.ultrasoundgel.org \\
\hline Emergency Ultrasound & Podcast & Lectures on bedside ultrasound & $\begin{array}{l}\text { https://podcasts.apple.com/us/podcast/emergency-ul- } \\
\text { trasound/id429668403 }\end{array}$ \\
\hline Resus Ultrasound & App & $\begin{array}{l}\text { Reference application on how to use POCUS with images demonstrating } \\
\text { normal/abnormal and "how to images" (free) }\end{array}$ & $\begin{array}{l}\text { https://apps.apple.com/us/app/resus-ultrasound/ } \\
\text { id1033017112 }\end{array}$ \\
\hline $\begin{array}{l}\text { Pocket Emergency } \\
\text { Ultrasound }\end{array}$ & App & Atlas of normal valves when using POCUS (free) & $\begin{array}{l}\text { https://apps.apple.com/us/app/pocket-emergency-ul- } \\
\text { trasound/id921385842 }\end{array}$ \\
\hline SonoSupport & App & $\begin{array}{l}\text { Step-By-Step on how to perform POCUS exams and procedures } \\
\text { (free to \$9.99) }\end{array}$ & $\begin{array}{l}\text { https://apps.apple.com/us/app/sonosupport-clinical- } \\
\text { emergency-medicine-critical-care/id638608139 }\end{array}$ \\
\hline Ultrasoundpedia & App & $\begin{array}{l}\text { Brief descriptions of each exam, the role of US as it pertains to each } \\
\text { exam, limitations and step-by-step scanning techniques (\$1.99) }\end{array}$ & $\begin{array}{l}\text { https://apps.apple.com/au/app/ultrasoundpaedia/ } \\
\text { id581876379?ign-mpt = uo\%3D4 }\end{array}$ \\
\hline
\end{tabular}

EM, emergency medicine; POCUS, point of care ultrasound.

normal views and procedural pearls.

Social media is also a very engaging platform to find POCUS F_FOAM consumers. Instagram is an easy-to-use app to post images and videos and has capabilities to post multiple images and videos within one post. Also, posts are easily searchable with hashtags such as \#FOAMed \#POCUS, \#FOAMus, and others. Instagram allows you to "follow" the hashtags so that you can always be updated on the newest posts. Twitter has long been a championed media platform to distribute FOAM, and there are numerous POCUS FOAM based twitter accounts. Many of the above mentioned podcasts, apps, and websites use Twitter accounts to promote their content. There are several popular emergency ultrasound twitter accounts such as @POCUS_Society, @Pocusfoamed, @ACEP_EUS, and @Ultrasoundpod. In addition, many EM ultrasound divisions and fellowships use twitter as a forum to discuss interesting cases, novel techniques, and teaching pearls.

\section{CONCLUSION}

Standardized assessment of FOAM content quality is limited to a few resources which have been described in the literature. ${ }^{2,3}$ All the apps we evaluated were available both on the Apple and the Android store. We explored various F_FOAM ${ }^{4}$ websites, podcasts and apps and evaluated those that discussed EM POCUS. FOAM has the capability to enhance medical education by providing up to date concepts through influential resources ${ }^{6}$ to each individu- al's personal preference of media. Having a variety of F_FOAM websites, podcasts, apps, and social media sites provides clinicians the opportunity to learn and discover topics of interest to them. More importantly, users are able to review the information asynchronously in their optimal learning environment. Overall, this improves knowledge translation and provides a medium which will also improve knowledge retention.

\section{CONFLICT OF INTEREST}

No potential conflict of interest relevant to this article was reported.

\section{REFERENCES}

1. Burkholder TW, Bellows JW, King RA. Free open access medical education (FOAM) in emergency medicine: the global distribution of users in 2016. West J Emerg Med 2018;19:600-5.

2. Grock $A$, Paolo W. Free open access medical education: a critical appraisal of techniques for quality assessment and content discovery. Clin Exp Emerg Med 2016;3:183-5.

3. Zhi A, Husain A. Free open access medical education applications: a critical appraisal of techniques for quality assessment and content discovery. Clin Exp Emerg Med 2019;6:93-5.

4. Beck-Esmay J. Focused FOAMed: the learners lens [Internet]. [place unknown]: REBEL EM; 2019 [cited 2019 Jul 30]. Avail- 
Simone Rudnin, et al.

able from: https://rebelem.com/focused-foamed-the-learners-lens/.

5. Thoma B, Joshi N, Trueger NS, Chan TM, Lin M. Five strategies to effectively use online resources in emergency medicine.
Ann Emerg Med 2014;64:392-5.

6. Otterness K. Incorporating FOAM into medical student and resident education. Clin Exp Emerg Med 2017;4:119-20. 